\title{
Discussion on the Performance of Visual Humor in Animation
}

\author{
Zhaopo Shao \\ Academy of Fine Arts \\ Huanggang Normal University \\ Huanggang, China
}

\begin{abstract}
Animation is an audio-visual narrative art that serves the spiritual needs of the public, and bringing joy to the audience is the necessary condition for its existence. This paper explains the elements and expressive methods of visual humor in animation from the aspects of image bearing, emotional rendering, surreal parody, lens montage and so on. The research on it can not only expand the expressive form and content of animation, but also has exploratory significance in promoting the healthy development of domestic animation industry.
\end{abstract}

Keywords —animation; visual humor; image; action; rhythm

\section{INTRODUCTION}

The deficient analysis on visual humor of animation has become the biggest obstacle in the theoretical research of animation, and it is also an important factor to cause a lagged development of domestic animation films. Animation is an art form to interestingly tell about stories to the audience through the orderly change of visual images, for which an inseparable relationship must exist between humorous language and visual images.

"The word humor was originally a biological concept." [1] It means the human body fluid components and proportions marked by the famous doctor Hippocrates in the ancient Greek. "Now it widely refers to a unique comedy effect of funny things through aesthetical grasp, which is produced mainly by an aesthetic way of the aesthetic subject with a humorous and timeless wisdom." [2] Visual humor has entered the art stage as a kind of aesthetic language. As the digital technology enters the field of animation production, the visual humor attributes of animation has been developed, and many internationally renowned digital animation companies appear, such ad the US Pixar and DreamWorks, whose works are praised by the audience as "excellent works of visual humor for both the young and the old", whether from the economic benefit or from the artistic form innovation. This paper analyzes the expression principle of humor in animation creation from the perspectives of image, color, action and rhythm.

This article is the stage research result of Humanities and Social Sciences Research Project (project number: 17Q181) of Hubei Provincial Department of Education in 2017.

\section{IMAGE, THE BEARER OF VISUAL HUMOR}

The animated image is the actor in the film, the most intuitive visual part of the animation, has the functions of narrative and cultural transmission, and also can most arouse the resonance of audience in emotion or thought. Therefore, the integration of humorous elements and images is an important part of visual humor in animated films.

\section{A. Body Proportion to Enhance the Sense of Humor}

The proportion design of role must fully conform to the audience orientation of film and the narrative content, the proportion of role not only can show the relationship among the roles, but also reflect the character, age, gender, race, occupation of individual role, and further outline the profile of role. In the design of cartoon role, we generally take head as the measurement standard for the image design. In the art of painting, for the ideal proportion of the male, the height of the head is $1 / 8$ of the height, the width of the shoulder is about the height of two heads, the waist is slightly less than the height of one head, the width of the buttocks is smaller than that of the shoulder. While in the design of cartoon role image, the image of cartoon role is generally about the height of three heads "Fig. 1", the individual also has the proportion of $1: 1$ between the body and the head, which is different from the proportion in the art of painting and more represents the lovely features of role image and enhances the humor character of role image. In order to ensure the accurate proportion of all roles in different angle degrees, we generally make a full design including the front, the side and the back of the role of "Fig. 2".

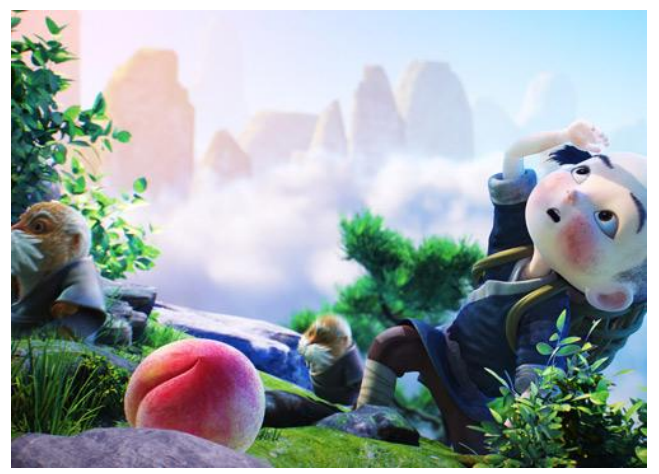

Fig. 1. The still of "Monkey King: Herois Back". 


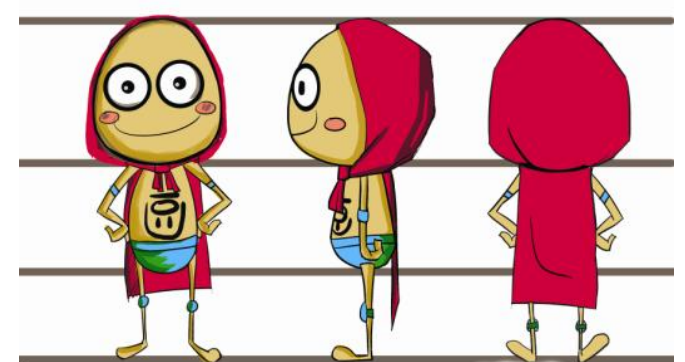

Fig. 2. Three views.

Face is an important part of the image, and the designer may use exaggerated expression technique for a certain part of facial features or advisedly cut down a certain part as to increase the humor character of cartoon role, which virtually increases the entertainment character of the image. For example, the genius rat in the "Ratatouille", has a big pink nose, pink ears and big eyes, for which the prototype of the role is exaggerated and deformed, greatly attracting the audience's eye, and additionally the exaggerated expression and action brings people a sidesplitting comedy effect in the vision.

\section{B. Structural Reorganization to Create A Sense of Humor}

Structural reorganization is a common way to express the image of the role, and it is a complex based on the real life, consciously making an anthropomorphic replacement of image structure of the role, so as to visually increase the appreciation of image. In the Chinese classic animation "Journey to the West", Pigsy's head is replaced into a pig's head to represent its greedy, lazy, timid and stupid features, such a element replacement not only narrows the distance with the audience, but also virtually increases the sense of humor of the role in the shape. Through the structural reorganization in the image design, animals, plants, and even abiotic object all can be endowed with human characteristics in the external features, emotions and personality by virtue of structural transplantation, so as to make animals, plants, or abiotic object more intuitively and novelly and interestingly represent the human emotions, and further reflect a real and interesting human society with good and evil.

\section{COlOR - EMOTIONAL ReNDERING OF Visual Humor}

"Color originally has no emotional content but it can cause the mental activity."[3] St. Augustine has said: "Beauty comes from the appropriate proportion of all parts, plus a pleasing color." [4] As the renderer of visual atmosphere in an animated film, color has the intuitional function of visual color for the "actor" costumes, props and others, so a good animation must have unique color aesthetic features. as a classic Kung Fu comedy animation film, "Kung Fu Panda" triggered a Chinese color aesthetics storm in the history of animation, the design of Panda Po in the black and white contrast brings the audience a strong visual impact, and the yellow pants set off a pleasant atmosphere, coupled with the simple and honest image feature, making the audience able to appreciate the humor and comedy of Po just from the senses of shape. This is the most typical visual humor form of single color. This form is mainly reflected by the simple colors in a complementary and strong visual impact. The complementary of colors has strong separation, so in the process of animated visual humor expression, it not only can increase the beautiful, functional and cultural features of the role, but also can make the audience feel different history and culture, different customs and aesthetic orientation, and make the audience experience the contradictory humor.

Animation screen color is more complex, not only related to the inherent color of the object, but also to the impact of light color on the lens screen. For example, the camera screen, in which a role is leisurely blowing flute in a fishing boat in the sea and playing with fish and sea mew, is a real portraiture of the typical oriental fisherman's life, and the concise and vivid screen color can increase the sensory entertainment of the audience from the tone of the screen.

\section{ACTION - SURREAL HUMOR}

\section{A. Role's Action}

"The action of animation role has its own different rules because of its different attributes, the psychological attributes of the role will be blended into the animation when the natural attributes of the role is represented." [5] So, action is a surreal parody humor of the animation designers to give full play to individual subjective initiative and to describe and sublime the director's intention and the dynamic plot in combination with their own, life experience, so as to make the action more perfectly reflect the character of the role.

"Parody, taking the aesthetic characteristics of the game as a coat and the imitation as a basic means of expression, is to carry out the reflection and thought, subversion and transcend in the text full of tension, and further to achieve the purpose of criticizing the right and wrong or the aesthetic effect of real entertainment and fun ."[6] Tom cat and Mouse Jerry mouse in the animation "Tom and Jerry" offer a surreal comic performance of the role action, which is the most successful masterpiece of parody. Chinese domestic classic animation "Uproar in Heaven" blends the performance art of China's traditional opera into the design of action, with a distinctive parody style and superb performance skills. Action humor can also be represented by the way of exaggeration and deformation, to achieve the amusing effect by setting parody with exaggerated expression and action. Such as the "Ratatouille", in which Xiao Lin placed mouse Xiao into his pants and brought it into the kitchen; due to Xiao Mi in the pants, Xiao Lin had to walk in a variety of weird posture; in order to guide Xiao Lin to cook soup, Xiao Mi crawled and gnawed in Xiao Lin's clothes to cause Xiao Lin's flap and jump of all kinds, like dancing; such funny actions are sidesplitting; Xiao Mi trained and guided Xiao Lin to do cooking by pulling his hair on Xiao Lin's head, bringing the audience countless dynamic visual humor. The creation of animation character image is diversified, including more common animal personification, plant personification, abiological personification as well as 
misplaced human-object personification and so on; how to make a rational performance of non-human drama and characteristics is also the premise for the audience liking the animation.

\section{B. Change of Expression}

Expression design is an important part of the role action parody, and the accurate and vivid expression not only has conducive to the representation of role character, but also very easily shakes the audience's mind. The creation of role expression should be made on base of normal changes of human face, master the external features of image and the plot bearing, and use the exaggeration and personification and other performance techniques, highlight the role's structure, shape, facial features and other major parts, to make the expression harmonious and interesting in plot and make the image have a sense of humor. Such as "Kung Fu Panda", in which Po has a rich expression and a obese body to form a striking contrast, promoting the honest image of Po and enhancing the humor of plot "Fig. 3". In the expression design of animated character, the symbolic design of concept can be used for a standard, so as to fully reflect the parody in the expression design process.

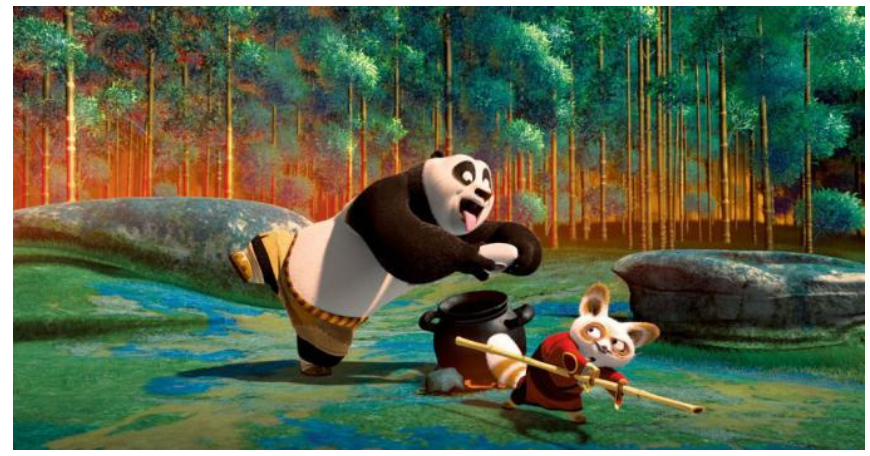

Fig. 3. Po's expression.

The expression of animated character comes form the real life, which is represented by the original artist with the artistic technique of exaggeration and deformation after summary, extraction and conclusion of human expression movement rules. The roles in the Pixar animation films never lack of lively and interesting expression, such as "Ratatouille", having a good expression. In the film, a old lady is shooting at Xiao Mi and its brother with a shotgun, but accidentally the chandeliers and ceilings are also hit down, and then she finds a mouse nest hidden on the ceiling, so countless mice and the ceiling fell together, the old lady shouted out, with a unbelievable and terrified expression on her face, for which the current network buzzword "shocked" can be used, making people can not help laughing.

\section{Montage - THE Humor From THE SuddeN CHANGE OF LENS}

Montage (French: Montage) is a foreign language of transliteration, and is originally an architectural terminology, meaning the composition and assembly, and when used in the animated film, it has the meanings of connecting and composing. The sudden change in the animation is mainly purposed to cause the audience's a series of storyline association through the lens editing, synthesis and sudden change of rhythm. This is the montage of lens, which not only affects the narrative logic of the story, but also affects the audience's visual and psychological feelings.

Lens is the basic unit of the film, and single or multiple lenses have a narrative function. Such as "Monkey King: Herois Back", has a distance screen with empty sky, setting off the magnificent momentum of the film, delivering Monkey King's bleak life background, setting a suspense for the plot. The conversion between the lenses easily gives the audience thinking, and the basic way of lens conversion is editing and synthesis, driving a unexpected changes in the development of event and further bringing the audience a visual pleasure. From "Mouse going cross the street, everyone chases it", we can see the image and status of mouse in our minds, while in the " Ratatouille", a mouse can be a chef, how amazing it is, no one can accept it in the chef circle and even in the real human society, but the mouse Xiao Mi achieves the dream through its efforts "Fig. 4".

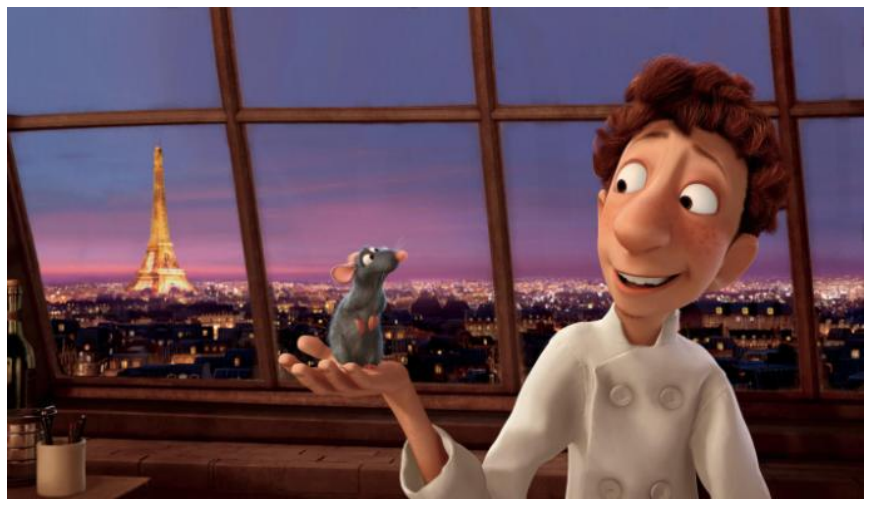

Fig. 4. The still of " Ratatouille ".

This practice is unprecedented, so that the film's lens narrative is full of freshness and humor. So, whether a single lens or the sudden change among lenses, serves the plot development, and the sudden change of lens also has a humor composition of the story. "The rhythm in the film means a way to produce a variety of effects by introducing or following or breaking the appreciation habits according to the psychological characteristics of the audience in watching film." [7] The visual rhythm of animation film mainly uses the editing and synthesis to bring a visual gap, so as to make the audience produce an unexpected sense of humor. Lens rhythm mainly serves the animation narrative, but of course, some experimental animations are designed to completely give the audience a sensory enjoyment, and not focus on the story narrative. In short, in the creation of animated film, the editing plays a vital role, and it is the second creation of art, so the performance of lens clip rhythm is the key element for an excellent animation film.

\section{CONCLUSION}

As an important performance form of animation, visual humor is also one way to touch the audience's emotion. 
European and American animation films have a unique way of visual humor performance, which is also the key to winning the audience and the market. However, there are differences in cultural aesthetics, so it is difficult to get the recognition of the audience if we mechanically copy the visual humor performance type in our domestic animation films in disregard of specific conditions, which has been proved. It has great significance for us to stand our national cultural attributes and explore the humorous visual element performance way suitable for our current animation films.

\section{REFERENCES}

[1] (Germany) Ripus. Comedy and humor [A]. translated by Liu Bannong, edited by Wu Lifu \& Hu Jingzhi. Masterpiece Collection of Western Literary Theory [C]. Beijing: Peking University Press, 1986.

[2] Zeng Yanbing: "The Historical Trend of Humor Aesthetic Character - from "Classical Humor" to "Black Humor", "Contemporary Foreign Literature", 1997.4.

[3] Ge Lu, Yang Junshun, Li Quanqing: "Color Emotion and Application of Product", "Decoration", 2005.2.

[4] Zhu Guangqian: "History of Western Aesthetics", People's Literature Publishing House, Beijing, 1979, p. 125.

[5] Huang Dawei: "The Movement Role in Animation ", "New Art", 2007.4.

[6] Xu Kun. " The parody of American TV Animation", "China TV" 2012.8.

[7] Li Xiang. "Innervation, Rhythm and Visual Communication - The Style Features of Hong Kong Films in the 1990s", "Contemporary Films", 2005.4. 